\title{
Effect of Spot-Welding Current-Cycle for Medium Carbon Steel And Stainless Steel on Mechanical Properties
}

\author{
Nawzad J.Mahmod ${ }^{1}$, Aysha Sh. Hasan ${ }^{2 *}$, Ahmed A.Hussein ${ }^{3}$, Obed M. Ali ${ }^{4}$ \\ 1,2,3 Kirkuk Technical College, Northern Technical University, 36001 Kirkuk, Iraq \\ ${ }^{4}$ Renewable Energy Research Unit, Northern Technical University, 36001 Kirkuk, Iraq \\ *Corresponding author E-mail: eng_aysha@yahoo.com
}

\begin{abstract}
Spot welding involves the joining of two or more plate metals in localized areas where melting and jointure of a little volume of fabric happens from heating caused by resistance to the passage of an electrical current. This process is typically used for obtaining a lap joint of plate metal parts. In this work, stainless steels and medium carbon steel were used. Three rules for welding set-up, lowest tap on the fastening electrical device, highest \% current setting on the weld management and shortest weld time setting on the weld management were adopted. Experiments conducted to show the effect of these variables on the welding diameter and tensile strength for each sample for medium carbon steel and stainless steel separately and joining both metals together by spot welding. The results show that the utmost durability was at stainless steel specimens and minimum tensile strength was at medium carbon steel specimens. Furthermore, the obtained results showed that the maximum heat generated was at stainless steel specimens and minimum heat generated values was at medium carbon steel specimens for all current dependent in this work. Meanwhile, slight effect of heat generated on the spot diameter for the current of $10.6 \& 5.3 \mathrm{kA}$, and so significant effect on the spot diameter for the last current $(2.3 \mathrm{kA})$.
\end{abstract}

Keywords: current-cycle, Mechanical properties, Medium carbon steel, Spot welding, Stainless steel, Tensile test.

\section{Introduction}

Resistance spot welding (RSW) may be a method that has been widely used in sheet metals production with benefits of high speed, suitableness for automation and inclusion in high-production assembly lines with completely different fabricating operations (Cho and Cho 1989). Resistance spot welding is extensively used for the production assembly of the all-steel body of cars and its part flat solid elements. In the spot fastening method, a weld lump can begin to make once decent energy has been placed into the weldment zone to boost the fabric to the solidus-liquids temperature of the joined materials and hence to start the forming of a molten weld pool. The value and time of the present and therefore the resistance of the workpieces confirm the scale of the formed lump (Salem 2011).

It differs from different fastening strategies in this no filler is used, and mechanical force is applied to forge weld the heated zone (Hulst 1969).

The diameters of the attachment spots outline the quality of a joint which are often monitored by victimisation, parenthetically, destructive testing. The destructive testing joint is torn apart, and also the diameters of the spots are inspected("TWI World Centre for Materials Joining Technology, Information Available at Their" 2003).

The current is controlled by two methods:

- The setting of the electrical device switch determines the most quantity of weld current accessible.

- The $\%$ of current management determines the $\%$ of the offered current to be used for creating the weld.

2. Literature review:Hakan Aydin et al. studied the tensile shear deformation and failure energy of the joints augmented with in- creasing the time cycle on the opposite hand, the indentation depth augmented virtually linearly with increasing the time cycle(Aydin, Tutar, and Bayram 2016). Marius Chirileanu et al. showed that different current values and time at constant pressure (force) of the electrodes for three types of welded materials. The specimens are subjected to tensile shear tests and also the surfaces of the failures were analyzed by scanning microscopy (SEM), maximum welding joint parameters were developed (Marius Chirileanu, Nistoroschi Georgiana, and Eugen Axinte 2013). T.Umasankai et al. showed that spot welding machine is appropriate for weld chrome steel and iron sheets with optimum weld parameters which is welding time and current (Umasankari et al. 2017).

Milan Brozek et al. the allotted tests showed that mistreatment of the operating variables counselled by the researcher, however, the longer attachment times, will acquire stronger welds(Niedermeier 2017).

R.K Rajkumar et al. showed that arise in the strength of samples due to a rise in the current with a constant time cycle for 304 austenitic stainless steel [9]. Nachmini Charde et al. showed that the tensile forces increase with current and weld time values until the failure limit happens(Charde and Rajkumar 2013)

\section{Materials and Methods}

Resistance spot welding (RSW) may be a method that has been widely used in sheet metals production with benefits of high speed, suitableness for automation and inclusion in high-production assembly lines with completely different fabricating operations (Cho and Cho 1989). Resistance spot welding is extensively used for the production assembly of the all-steel body of cars and its part flat solid elements. In the spot fastening method, a weld lump can 
begin to make once decent energy has been placed into the weldment zone to boost the fabric to the solidus-liquids temperature of the joined materials and hence to start the forming of a molten weld pool. The value and time of the present and therefore the resistance of the workpieces confirm the scale of the formed lump (Salem 2011). It differs from different fastening strategies in this no filler is used, and mechanical force is applied to forge weld the heated zone (Hulst 1969). The diameters of the attachment spots outline the quality of a joint which are often monitored by victimisation, parenthetically, destructive testing. The destructive testing joint is torn apart, and also the diameters of the spots are inspected(“TWI World Centre for Materials Joining Technology, Information Available at Their" 2003).

The current is controlled by two methods:

- The setting of the electrical device switch determines the most quantity of weld current accessible.

- The $\%$ of current management determines the $\%$ of the offered current to be used for creating the weld.

2. Literature review: Hakan Aydin et al. studied the tensile shear deformation and failure energy of the joints augmented with increasing the time cycle on the opposite hand, the indentation depth augmented virtually linearly with increasing the time cycle(Aydin, Tutar, and Bayram 2016). Marius Chirileanu et al. showed that different current values and time at constant pressure (force) of the electrodes for three types of welded materials. The specimens are subjected to tensile shear tests and also the surfaces of the failures were analyzed by scanning microscopy (SEM), maximum welding joint parameters were developed (Marius Chirileanu, Nistoroschi Georgiana, and Eugen Axinte 2013).

T.Umasankai et al. showed that spot welding machine is appropriate for weld chrome steel and iron sheets with optimum weld parameters which is welding time and current (Umasankari et al. 2017).

Milan Brozek et al. the allotted tests showed that mistreatment of the operating variables counselled by the researcher, however, the longer attachment times, will acquire stronger welds(Niedermeier 2017).

R.K Rajkumar et al. showed that arise in the strength of samples due to a rise in the current with a constant time cycle for 304 austenitic stainless steel [9]. Nachmini Charde et al. showed that the tensile forces increase with current and weld time values until the failure limit happens(Charde and Rajkumar 2013)

\section{Results and Discussions}

Medium carbon steel and austenitic stainless steel 304L samples were used in the research, and the chemical composition of each sample is shown in table-1and 2, analyzed by material analysis division.

Table1: the chemical composition of medium carbon steel

\begin{tabular}{|l|l|l|l|l|l|}
\hline$\% \mathrm{C}$ & $\% \mathrm{Fe}$ & $\% \mathrm{Mn}$ & $\% \mathrm{~S}$ & $\% \mathrm{Si}$ & $\% \mathrm{P}$ \\
\hline 0.3 & 98.033 & 1.23 & 0.013 & 0.41 & 0.014 \\
\hline
\end{tabular}

Table2: The chemical composition of austenetic stainless steel 304L

\begin{tabular}{|l|l|l|l|l|l|l|}
\hline$\% \mathrm{C}$ & $\% \mathrm{Ni}$ & $\% \mathrm{Si}$ & $\% \mathrm{Cr}$ & $\% \mathrm{Mn}$ & $\% \mathrm{Fe}$ & $\% \mathrm{P}$ \\
\hline 0.03 & 8.5 & 0.9 & 18 & 1.5 & 65 & 0.04 \\
\hline
\end{tabular}

The samples are joined with one spot weld located at the middle of the overlapped region; the sample is then forced tension because of the offset of the sheets applying of tension which creates a bending moment that causes rotation of the weld lump. The dimension of the specimens was selected according to (ANSI/AWS for $0.5 \mathrm{~mm}$ thickness, $80 \mathrm{~mm}$ length and $20 \mathrm{~mm}$ width) as described in figure- 1 the sheet materials were cut by using a plate machine shearer. The specimens were joined as lap joints as shown in figure 2; the formula calculates the diameter of the electrode:

$d=6 \sqrt{t}$, where:

$\mathrm{d}$ : electrode diameter $(\mathrm{mm})$ $\mathrm{t}$ : thickness of plate sheet $(\mathrm{mm})$

$\mathrm{d} \approx 4 \mathrm{~mm}$ (ANSI/AWS C1.4, American Welding Society), and a tapered electrode shape were used in the experiment's

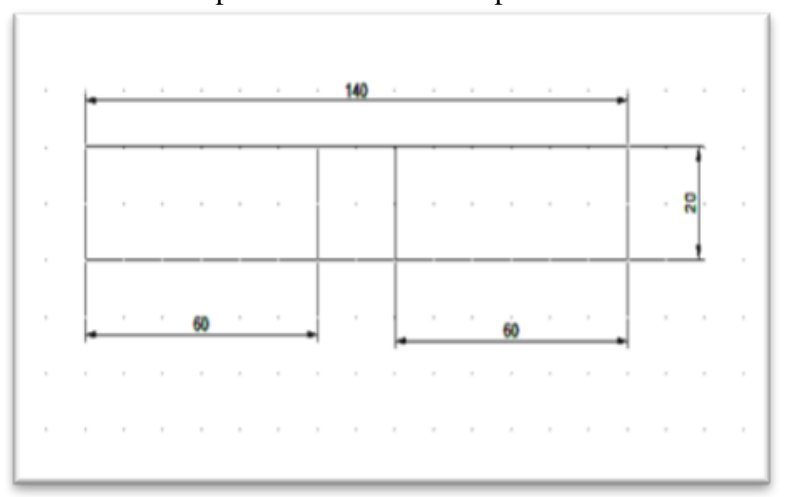

Fig.1: Dimension of resistance spot welding specimen (mm)

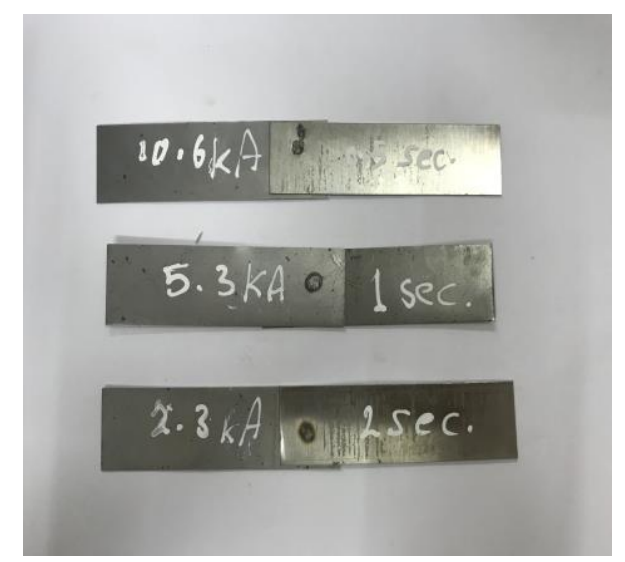

Fig. 2: Specimens used in resistance spot welding ( $\mathrm{mm})$

Sheets surfaces to be welded should be clean, free from oxides and chemical compounds, and have a soft surface. Spot welding machine, type TELWIN PTE 18, shown figure (3) used in this study. 


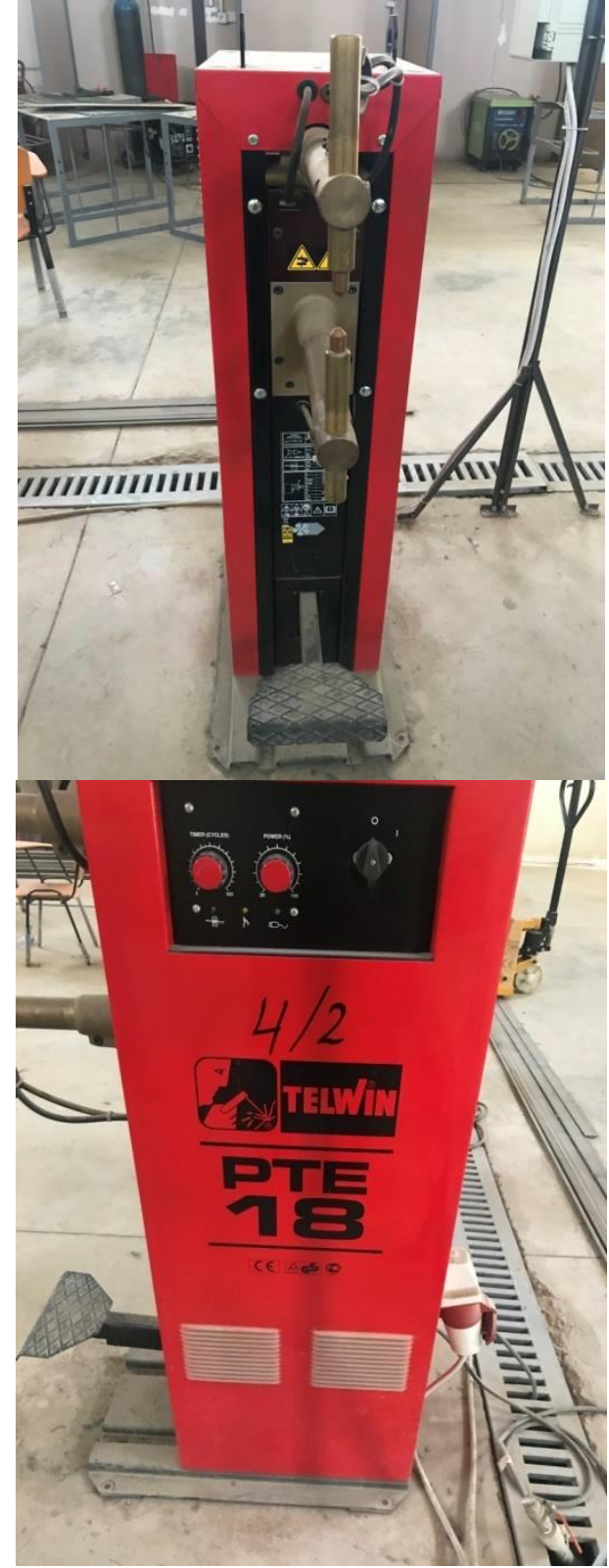

Fig. 3: Spot welding machine used in the work

An important step before beginning the attachment method is to run on the cooling water system in the machine for cooling the electrodes, this is often to chill the electrodes throughout the attachment method. Medium carbon steel samples and stainless steel samples were welded by using the mentioned welding procedures, and then dissimilar samples of medium carbon steel and stainless steel were welded by using the same procedure.

The following Rules for a Welding Set-Up are used:

1- Use the maximum current setting welding control.

2- Use the minimum welding time (cycle) setting welding control. These rules can facilitate produce sensible welds systematically and supply for the foremost economical use of the machine, electrically, automatically, and thermally, in this experiment, the welding time and current were varied to see their effect, while the electrode tips and the force applied are constant (Controls 2014).

In put Voltage: $400 \mathrm{VOLT}$

In put current: $10.6 \mathrm{kA}$

Max. Force applied by pedals: $190 \mathrm{~N}$

Water flow rate: $2.5 \mathrm{l} / \mathrm{min}$

Each sample is stamped by using a permanent special marker, then, using a graduated lens the diameter of the weld area was measured to show the extent of thermal expansion of each specimen as shown in figure (4).

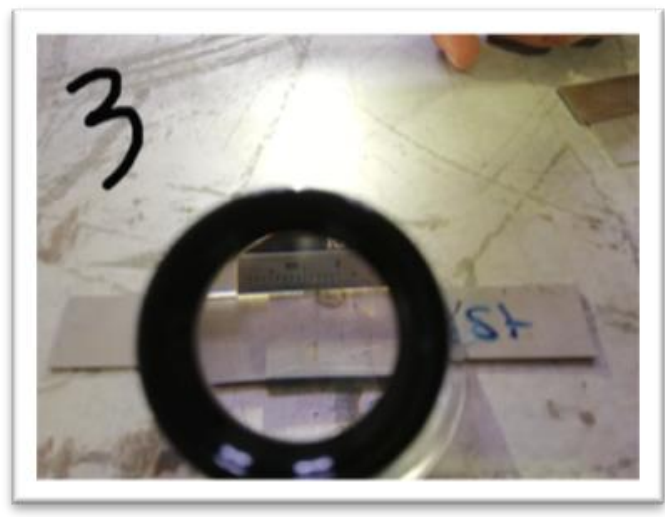

Fig.4: Graduated lens measurement

This amount of heat generated is calculated as a function of time, current is expressed according to Joules law by the formula:

$H=I^{2} R t$

Where:

H: Heat generated (Joule)

I: Current (Ampere)

R: Specific resistivity $(\mathrm{Ohm})$

t: Time (seconds) (Raut and Achwal 2014).

$R=\rho \cdot \frac{L}{A}$

Where:

$\mathrm{R}$ : End to end tracks resistance force in ohm

$\rho$ : Electrical resistivity (ohm. Meter)

L: Length of sample (meter)

A: Cross section area $\left(\mathrm{m}^{2}\right)($ Chardi 2013).

The welding samples subjected to tensile-shear test using the electrical resistivity of the austenitic stainless steel $304 \mathrm{~L}$ is $\left(7.20 * 10^{-7}\right.$ $\Omega-\mathrm{m})($ ANSI/AWS C1.4, American Welding Society), for medium carbon steel $\left(1.630^{*} 10^{-7} \Omega-\mathrm{m}\right)$, and for the electrode cop$\operatorname{per}\left(1.72 * 10^{-8} \Omega-\mathrm{m}\right)$ (Controls 2014).

Figures (5), show that the maximum obtained tensile strength value $(12.4 \mathrm{kN})$ achieved at the maximum current $(10.6 \mathrm{kA})$ for stainless steel specimens which means that when the current is increased the tensile strength is also increases (Chardi 2013). It ended that the joining current at the correct time throughout the operation of the joining machine may be a performance of the fastening management this result was reported by Aravinathan and C. Nachimani(a. Aravinthan and C. Nachimani 2011). The heat affected zone (HAZ) of the medium carbon steel is broader because of the upper thermal physical phenomenon of the stainless steel. Therefore, it may be explicit that the upper welding current that used the larger the fusion zone. Moreover, it was recorded for medium carbon steel the strength value $(12.3 \mathrm{kN})$ at the current $(10.6 \mathrm{kA})$. While, the relative durability of stainless steel was recorded due to the fact that the mineral thickness is similar and the same current and time. This is proven by the researcher Ladislav Kola et al. (Kola` et al. 2012). 


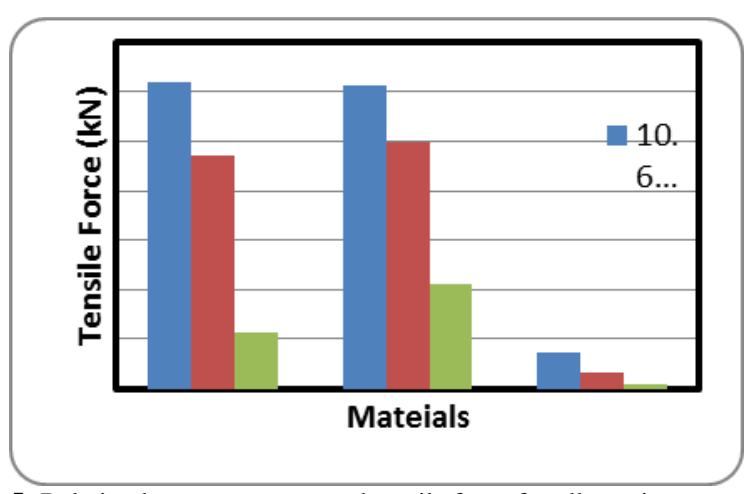

Fig. 5: Relation between current and tensile force for all specimens.

Figure $(6,7 \& 8)$ shows that the maximum heat generated in the stainless steel specimen was 647Joule with spot diameter $5 \mathrm{~mm}$. While the maximum heat generated for medium carbon steel 146Joule with spot diameter $4.7 \mathrm{~mm}$. Dissimilar joint between stainless steel and medium carbon steel specimens shows maximum heat generated 397Joule with spot diameter $5 \mathrm{~mm}$ for the stainless steel side welding. However, the heat generated value of 397Joule for the other side with spot diameter $4.7 \mathrm{~mm}$. The conclusion is that when the welding current increases the nugget size will increase and the nugget size is related to the diameter of the spot, this is approved by the researcher J.B.Shamsul et al. (Shamsul and Hisyam 2007). Equation (2), shows the effect of the electrical resistivity of the material.

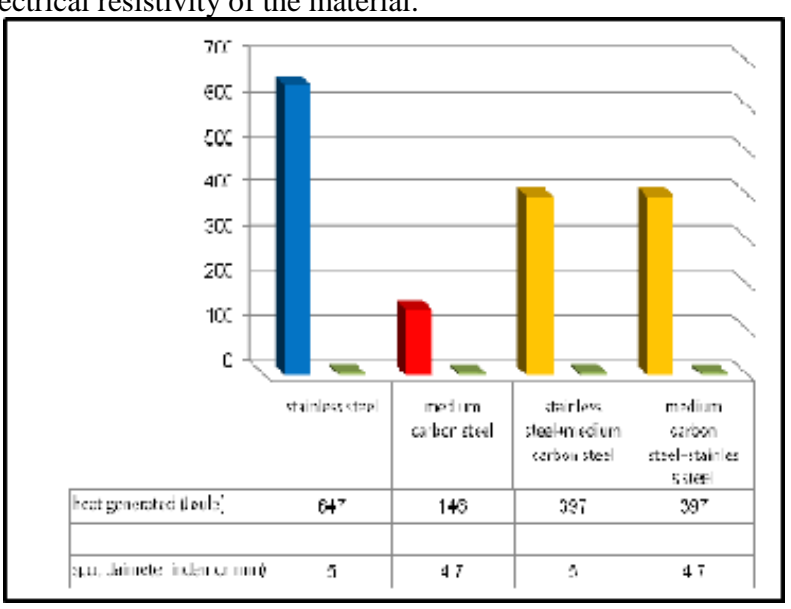

Fig. 6: Relation between heat generated \& spot diameter at (10.6kA) and $(0.5 \mathrm{sec}$.

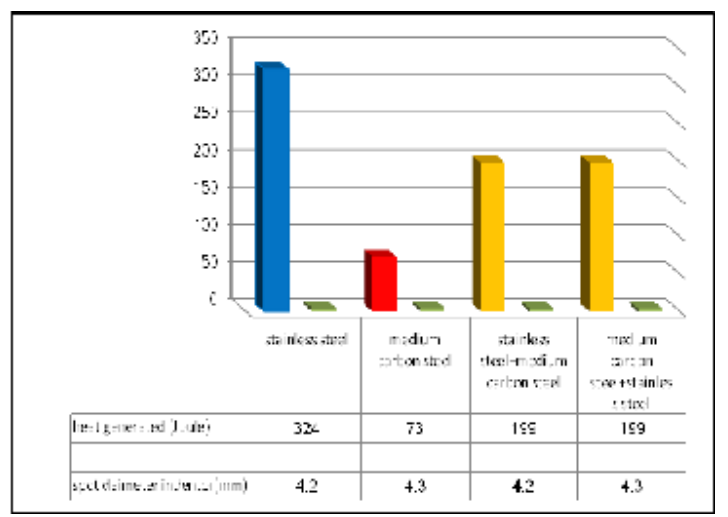

Fig. 7: Heat generated \& spot diameter relation at $(5.3 \mathrm{kA})$ and $(1 \mathrm{sec}$.)

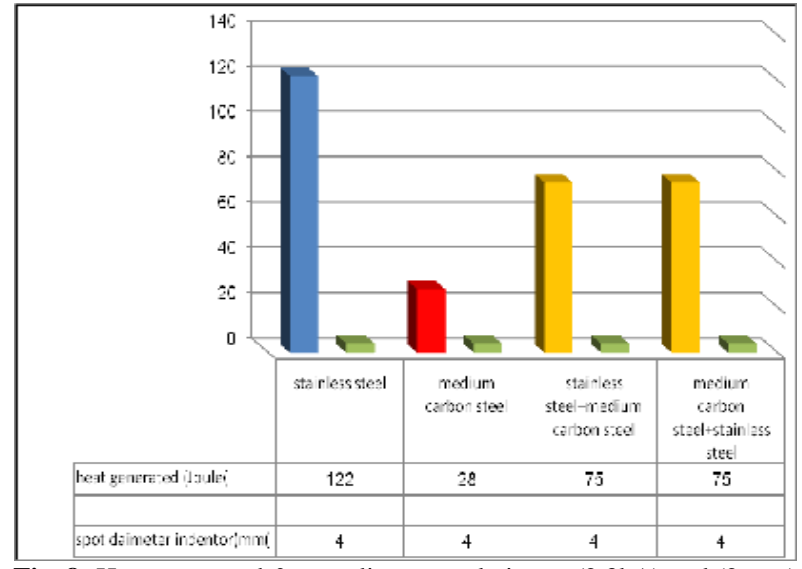

Fig. 8: Heat generated \& spot diameter relation at $(2.3 \mathrm{kA})$ and $(2 \mathrm{sec}$.

The maximum heat generated value was at the current $(10.6 \mathrm{kA})$ for the stainless steel specimens and meanwhile, the minimum heat generated value was at the current $(2.3 \mathrm{kA})$ for the same specimens. Equation (2) represents the effect of the electrical resistance shown in the results. For the dissimilar specimens, heat generated values were the maximum at the current $(10.6 \mathrm{kA})$. Meanwhile, the minimum value was at the $(2.3 \mathrm{kA})$. The dissimilar specimens heat generated value was the same for the two types of joints, because of the calculation producer of the electrical resistance value, all those shown in figures $(6,7$ and 8$)$.

\section{Conclusions}

Spot welding involves the joining of two stainless steel and medium carbon steel plates in this study. From the obtained results the following findings are concluded:

The tensile strength values were obeyed the following rules for all current dependent in the work:

Stainless steel specimens> Medium carbon steel specimens > Dissimilar specimens

The heat generated values were obeyed the following rules for all current dependent in the work:

Stainless steel specimens> Dissimilar specimens > Medium carbon steel specimens. The small effect of heat generated on the spot diameter for the (10.6 \& $5.3 \mathrm{kA})$ current and no significant effect on the spot diameter for the last current $(2.3 \mathrm{kA})$ for all the specimens used in the work with different types of materials.

\section{References}

[1] A. Aravinthan and C. Nachimani. 2011. "Analysis of Spot Weld Growth on Mild and Stainless Steel.” Welding Journal 90 (August): 143-147.

[2] ANSI/AWS C1.4, American Welding Society. "Spec -ification for Resistance Welding of Coated and Uncoated Carbon and Low Alloy Steels," 91-98.

[3] Aydin, Hakan, Mümin Tutar, and Ali Bayram. 2016. "The Influence of Welding Time on Mechanical Properties of Resistance Spot Welded TWIP Steel Sheets.” Xiii International Scientific Congress Machines. Technologies. Materials. 2016 Summer Session 14 17.09.2016 Varna, Bulgaria 2 (August): 16-19.

[4] Charde, Nachimani, and Rajprasaad Rajkumar. 2013. "Investigating Spot Weld Growth on 304 Austenitic Stainless Steel (2 Mm) Sheets." Journal of Engineering Science and Technology 8 (1): 6976.

[5] Chardi, Nachmini. 2013. "An Experimental Investigation on Spot Weld Growth on Dissimilar Joint of 304austenitic Stainless Steel and Medium Carbon Steel Part -1." International Journal of Advances in Applied Sciences(IJAAS) 2 (1): 25-32.

[6] Cho, Hs, and Yj Cho. 1989. "A Study of the Thermal Behavior in Resistance Spot Welds.” Welding Journal, June.

[7] Controls, Entron. 2014. "Resistance Welding Controls and Applications" 7 (864): 1-62. 
[8] Hulst, A. P. A. J. 1969. "A Thermal Model of the Spot Welding Process Eindhoven: Technische Universiteit."

[9] Kola , Ladislav, Martin Sahul, Milan Tuř, and Michal Felix. 2012. "Resistance Spot Welding of Dissimilar Steels" 52 (3): 43-47.

[10] Marius Chirileanu, Nistoroschi Georgiana, and and Eugen Axinte. 2013. "Researches on the Failure Modes under Tensile Forces of the Resistance Spot Welding (RSW) Joints.” International Journa of Engineering Research and Applications (IJERA) 3 (2): 396-400.

[11] Niedermeier, Ota. 2017. "Resistance Spot Welding of Steel Sheets of the Same and Different Thickness" 65 (3): 807-814.

[12] Raut, Manoj, and Vishal Achwal. 2014. "Optimization of Spot Welding Process Parameters for Maximum Tensile Strength.” Int. J. Mech. Eng. \& Rob. Res. Manoj Raut and Vishal Achwal 3 (4).

[13] Salem, Meranda. 2011. "Meranda Ahmed Salem Control and Power Supply for Resistance Spot Welding ( RSW )," April.

[14] Shamsul,JB, and MM Hisyam.2007."Study of Spot Welding of Austenitic Stainless Steel Type 304.” Journal of Applied Sciences Research, May: 229-230.

[15] "TWI World Centre for Materials Joining Technology, Information Available at Their." 2003.

[16] Umasankari, T, V Balaji, P Balamurugan, R Balaji, and B Balakumanan. 2017. "Design Optimization and Analysis of Spot Welding In SS202 and GI Sheet,"(4): 4-7. 